\title{
Capecitabine/Trastuzumab Regimen
}

National Cancer Institute

\section{Source}

National Cancer Institute. Capecitabine/Trastuzumab Regimen. NCI Thesaurus. Code C138033.

A chemotherapy regimen consisting of capecitabine and trastuzumab, used as a treatment for recurrent and metastatic HER-2/neu-positive breast cancer. 